\title{
Natural Ventilation of Smoke Subject to Wind Pressure Within Fire Safety Engineering Approach
}

\author{
Rachid Fakir*, Noureddine Barka, Jean Brousseau \\ Department of Mathematics, Computer Science and Engineering, University of Quebec at Rimouski, Rimouski, Canada
}

Email address:

rachid.fakir@uqar.ca (R. Fakir)

*Corresponding author

\section{To cite this article:}

Rachid Fakir, Noureddine Barka, Jean Brousseau. Natural Ventilation of Smoke Subject to Wind Pressure within Fire Safety Engineering Approach. Engineering Physics. Vol. 2, No. 1, 2018, pp. 23-31. doi: 10.11648/j.ep.20180201.15

Received: August 17, 2018; Accepted: September 3, 2018; Published: September 25, 2018

\begin{abstract}
This paper presents an analytical model able to explore the design method of natural smoke evacuation through an exhaust vent subject to wind pressure. The proposed model can be used to determine the flow rate of smoke and the optimal section of the exhaust vent according to the geometric parameters of the room, the heat release rate and the pressure exerted by the wind forces at the exhaust vent. The numerical resolutions of the mathematical equations of the model were performed using the dichotomy method. The proposed analytical approach is built progressively by, (i) the examination of interaction forces between buoyancy forces and wind pressure forces, (ii) a numerical validation of the analytical model using the numerical simulation software Fire Dynamics Simulator, and (iii) proposal of a method of approximation of the optimal section of the exhaust vent for a maximum smoke evacuation rate. The results show very satisfactory and provide adequate prediction of the optimal size of the exhaust vent between the theoretical approximation and various configurations of numerical simulation. The feasibility and effectiveness of the proposed approach lead to an accurate and reliable analytical model able to analyze the influence of the size of natural smoke evacuation vents subjected to the pressure of wind forces.
\end{abstract}

Keywords: Fire in Confined Spaces, Natural Ventilation of Smoke, Wind Forces, FDS-6.5.3, CFAST-7.3.0

\section{Introduction}

Fire safety engineering [1], which identifies the risks and their mitigation, owes its success to modeling the development of flames, fumes and criteria associated with safety objectives such as heat flow, the clearance height, evacuation outside the fumes, heat, gases and unburned products, etc. [1, 2]. To meet these specific needs, the dedicated software has been developed to simulate the distribution of heat flow and fumes, taking into consideration the complexity of the factors associated with the building, such as geometry, the ventilation system and the smoke evacuation system $[3,4]$. The numerical simulations allow evaluation of the performance of the smoke evacuation, including in the case of presence of wind pressure forces. When a fire starts in a naturally ventilated room, the smoke is stratified under the ceiling and then evacuated through smoke extraction openings located in the upper part of the room. Natural smoke extraction facilities [5] are fixed equipment that are activated by the effect of thermal ascendancy to evacuate and direct smoke and heat to the outdoors in a controlled way. These devices also serve to protect buildings in case of excessive heat stress. These smoke and heat extraction facilities have to complied, designed, sized [6], and maintained to be effective and ready to work anytime. Installation of smoke extraction systems and heat extraction, requires air renewal openings for efficient smoke and heat evacuation to the outside [7]. The openings allowing this renewal of air, such as openings in the facades, doors and windows, are usually placed near the ground. The wind blowing on a building creates pressure and depression on its surface, which varies with time and wind direction [8].

This pressure differential greatly influences the sizing of the smoke exhaust vent. The purpose of this study is to propose an analytical model for controlling the design parameters of the smoke exhaust vent under the influence of wind pressures, to improve the fire engineering zone-codes. The analysis process is built by (1) a simulation of a case study, (2) development of an analytical model giving the optimal section of the smoke exhaust vent for a maximum extraction flow while taking into account the wind speed, and 
(3) an analysis of the results of the simulations and discussion, to show the advantages and disadvantages of using zone-codes vis-a-vis CFD codes for different wind speeds.

\section{Analytical Model}

\subsection{Calculation Assumptions}

In the development of the analytical model, it was assumed that the cross-section of the room is sufficiently large so that the rising plume does not extend to the sidewalls. That the density of the smoke layer is uniform when the steady state will be established (stabilization of the variation of the height of the smoke layer). That the volumetric flow of smoke evacuated outside the room through the smoke extraction opening will be composed of a volume flow of air entering through the air renewal opening (the door of the room). It was also considered that the pressure exerted by the force of the wind in uniform distribution and a distribution perpendicular to the surface of the smoke exhaust vent, by using the approximation of the Master-couple and frontal surface subject to the forces of the wind. The Master-couple may be smaller than the frontal surface in the case of a wind direction with an angle of inclination relative to the wall surface.

\subsection{Smoke and Gas Evacuation}

Figure 1 shows a room with a floor area $\mathrm{S}$ with two openings, an air inlet opening and a smoke exhaust vent having surfaces $S_{1}$ and $S_{2}$ respectively. A heptane fire with Heat Release Rate, $\psi_{t}$, is positioned in the center of the room. Smoke exhaust vent is subject to wind pressure and, the opening of the air inlet is positioned sheltered from the wind. The effect of the wind is generated by the sky blue surface. The surfaces represented by the white color denotes a passive opening to the outside so as not to affect the flow pattern and thus simulates real wind.

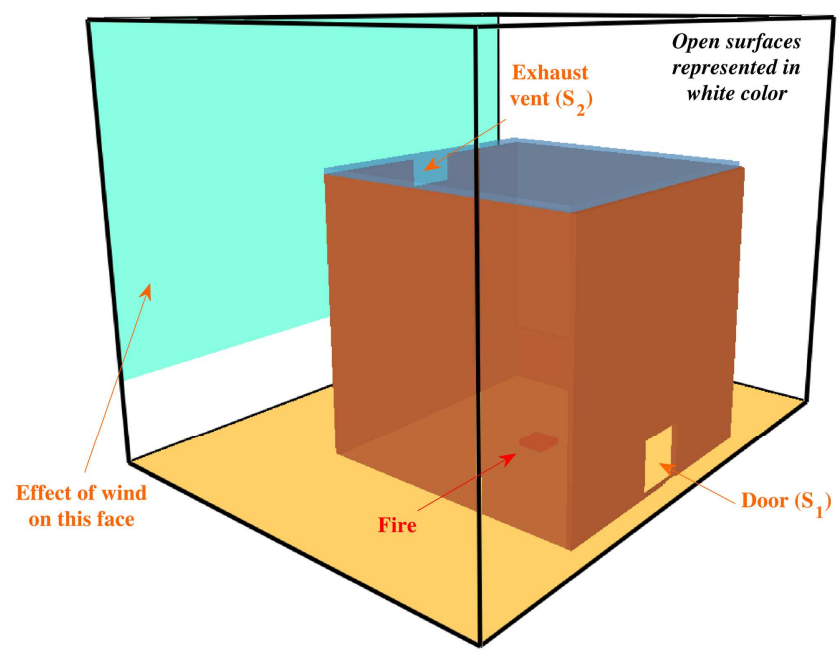

Figure 1. Schematic representation of the studied case.

Figure 2 shows a cross section of the studied room after stabilization of the variation of the height of the smoke layer. In steady state, we can apply Archimedes' theorem to the volume of outside air surrounding the geometry of the studied room to estimate the variation of pressure forces between the smoke exhaust vent surface, which is subject to the forces of the wind, and air inlet opening, which is not subject to the forces of wind pressure. This approximation at equilibrium, for a stable thickness of the smoke layer, allows expressing the value of the external pressure at a height $\mathrm{H}$ by subtraction of the weight of the air layer using the pressure $\mathrm{P}_{0}$ and the gap between the levels of the openings. This hypothesis is valid for low wind speeds or in the case of a dominance of buoyancy forces on wind pressure forces. We find in the study of P. F. Linden [9] similar design rules explaining that even though the wind seems to be the dominant driving mechanism, it is important to take into consideration that buoyancy forces can greatly influence thermal fluxes in space.

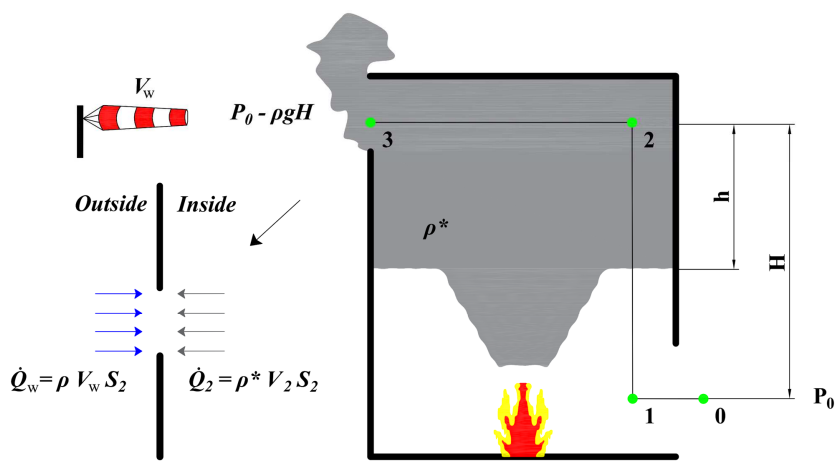

Figure 2. Schematic visualisation of cross-section of the studied building.

By applying Bernoulli's theorem along the current lines $(0$, $1),(1,2)$ and $(2,3)[10]$, it is possible to write and formulate at the positions 1,2 and 3 , the pressure values as a function of the value of the pressure at the previous position:

$$
\begin{gathered}
\mathrm{P}_{0}=\mathrm{P}_{1}+1 / 2 \rho \mathrm{C}_{1} \mathrm{~V}_{1}^{2} \\
\mathrm{P}_{1}=\mathrm{P}_{2}+\rho^{*} \mathrm{gh}+\rho \mathrm{g}(\mathrm{H}-\mathrm{h}) \\
\mathrm{P}_{2}=\mathrm{P}_{3}+1 / 2 \rho \mathrm{C}_{2} \mathrm{~V}_{2}^{2}=\mathrm{P}_{0}-\rho \mathrm{gH}+1 / 2 \rho \mathrm{C}_{2} \mathrm{~V}_{2}^{2}
\end{gathered}
$$

With $\mathrm{C}_{1}$ and $\mathrm{C}_{2}$ respectively are singular pressure loss coefficients at the air inlet opening and smoke exhaust vent [11]. For a flow of fire smoke unidirectional from inside to outside (smoke extraction), the wind pressure forces must be lower than the pressure forces of the smoke layer. Therefore, the condition of equation 4 must be satisfied:

$$
P_{2}>P_{3} \Leftrightarrow 1 / 2 \rho^{*} V_{2}^{2}>1 / 2 \rho V_{w}^{2} \Rightarrow V_{2}>V_{w} \sqrt{\rho / \rho^{*}}
$$

Equation 5 presents the mass flow balance for a representation of the smoke extraction flow depending on the volume flow of air entering by the exhaust vent without the resistance of the buoyancy forces of the smoke layer. Equation 6 shows the expression of the smoke extraction flow coming out of the exhaust vent without the resistance of 
the wind pressure forces. With $\rho$ and $\rho^{*}$, the densities of the air and the smoke layer. Hunt and Linden formulated in 1999 the expression of equation 6 for a similar flow without the presence of wind forces [12].

$$
\begin{gathered}
Q_{\text {ext }}=Q_{2}-Q_{w} \sqrt{\rho / \rho^{*}} \\
Q_{2}=\left(S_{1} S_{2} / \sqrt{\left(C_{1} S_{2}^{2}+C_{2} S_{1}^{2}\right)}\right) \sqrt{2 g h\left(\rho-\rho^{*}\right) / \rho^{*}}
\end{gathered}
$$

The filling of the room starts as soon as the plume hits the ceiling, which represents the initial moment of the model. In this case, the density of the initial layer which is formed at the ceiling is then $\rho(z)$. This same layer thickens, while it continues to be fed by the plume. The mass transfer between

the plume and the smoke layer takes place at an altitude $\mathrm{z}$, represented by a circle of diameter $\mathrm{d}(\mathrm{z})$, at a speed $\mathrm{u}(\mathrm{z})$. It is assumed that at all times, the density $\rho^{*}$ of the smoke layer is uniform. The equations 7,8 and 9 present the Heskestad equations formulated in 1984 [13], to represent the characteristics of the smoke plume (speed, diameter and density) for a heptane pool fire of diameter D.

$$
\begin{gathered}
\mathrm{u}(\mathrm{z})=10.3\left(0.7 \psi_{\mathrm{t}} / \mathrm{z}-1.32 \psi_{\mathrm{t}}^{2 / 5}+1.02 \mathrm{D}\right)^{1 / 3} \\
\mathrm{~d}(\mathrm{z})=0.24 \sqrt{\rho / \rho^{*}}\left(\mathrm{z}-1.32 \psi_{\mathrm{t}}^{2 / 5}+1.02 \mathrm{D}\right)
\end{gathered}
$$

Equation 10 presents the expression of the volume flow of smoke generated by a fire according to HRR and height (z) between the floor and the smoke layer. Expression deduced from equations 7 and 8 . When steady state will be established, the volume flow of smoke entering the smoke layer at a height $\mathrm{z}$ will be equal to the volume flow at the outlet of the smoke extraction opening. Equation 11 presents the balance of the volume flows at the smoke extraction opening. With $\rho^{*}$ introduced in equation 11 on the basis of the Heskestad formulation of equation 9.

$$
\begin{gathered}
Q_{\mathrm{v}}(\mathrm{z})=0.46\left(\mathrm{z}-1.32 \psi_{\mathrm{t}}^{2 / 5}+1.02 \mathrm{D}\right)^{5 / 3}\left(0.7 \psi_{\mathrm{t}}\right)^{1 / 3}+2.772 \psi_{\mathrm{t}} \\
\mathrm{Q}_{\mathrm{v}}=\mathrm{Q}_{\mathrm{ext}} \Leftrightarrow \mathrm{Q}_{\mathrm{v}}=\mathrm{Q}_{2}-\mathrm{Q}_{\mathrm{w}} \sqrt{\rho / \rho^{*}}
\end{gathered}
$$

Equation 12 presents the mathematical formula of predicting smoke volume flow, depending on the geometric dimensions of the room, the wind speed and the HRR. Table 1 gives the numerical values used in the calculations: room dimensions, HRR, wind speed, pressure drop coefficients and the heptane pool fire diameter.

$$
\begin{gathered}
\mathrm{f}(\mathrm{z})=0.4 \psi_{\mathrm{t}}{ }^{1 / 3}\left(\mathrm{z}-1.32 \psi_{\mathrm{t}}{ }^{2 / 5}+1.02 \mathrm{D}\right)^{5 / 3}-\sqrt{13.4 \mathrm{~g} \psi_{\mathrm{t}}{ }^{2 / 3}\left(\mathrm{z}-1.32 \psi_{\mathrm{t}}{ }^{2 / 5}+1.02 \mathrm{D}\right)^{-5 / 3}(\mathrm{H}-\mathrm{z}+\mathrm{L} / 2)} \times \\
\left(\mathrm{S}_{1} \mathrm{~S}_{2} / \sqrt{\left(\mathrm{C}_{1} \mathrm{~S}_{2}^{2}+\mathrm{C}_{2} \mathrm{~S}_{1}^{2}\right)}\right)+2.772 \psi_{\mathrm{t}}+\mathrm{V}_{\mathrm{w}} \mathrm{S}_{2} \sqrt{1+6.7 \psi_{\mathrm{t}}{ }^{2 / 3}\left(\mathrm{z}-1.32 \psi_{\mathrm{t}}{ }^{2 / 5}+1.02 \mathrm{D}\right)^{-5 / 3}}=0
\end{gathered}
$$

Table 1. Numerical parameters for computation.

\begin{tabular}{ll}
\hline Parameters & Numerical values \\
\hline $\mathrm{S}_{1}$ & $4-\mathrm{m}^{2}$ \\
$\mathrm{~S}_{2}$ & $2-\mathrm{m}^{2}$ \\
$\mathrm{~S}$ & $70-\mathrm{m}^{2}$ \\
$\mathrm{~L}$ & $2-\mathrm{m}$ \\
$\mathrm{H}$ & $8.5-\mathrm{m}$ \\
$\psi_{\mathrm{t}}$ & $500-\mathrm{kW}$ and $1000-\mathrm{kW}$ \\
$\mathrm{V}_{\mathrm{w}}$ & $0-\leq \mathrm{V}_{\mathrm{w}} \leq 10-\mathrm{m} \cdot \mathrm{s}^{-1}$ \\
$\mathrm{C}_{1}$ & 3.5 \\
$\mathrm{C}_{2}$ & 4.5 \\
$\mathrm{D}$ & $1.0-\mathrm{m}$ \\
\hline
\end{tabular}

Figure 3 shows the flowchart of solving equation 12 by the dichotomy method $[14,15]$. This algorithm makes it possible to give the value $\mathrm{z}$ for a total error in the exact solution not exceeding $10^{-6}-\mathrm{m}$. The solution $\mathrm{z}$ value of equation 12 gives the numerical expression of the volume flow that enters the smoke layer (and exits the smoke extraction opening) through the use of Heskestad correlations (Eq. 7, 8 and 9).

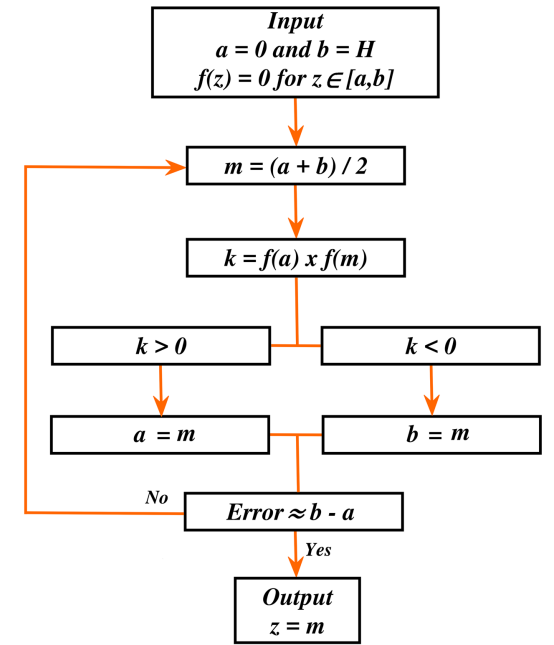

Figure 3. Numerical resolution flowchart of the Eq. 12.

\section{Validation of the Analytical Model}

CFD numerical simulations were performed using Fire 
Dynamics Simulator software (version 6.5.3) [16]. This software developed by the National Institute of Standards and Technology (NIST) uses simulation of large scales of turbulence and treats density changes on the assumption of low Mach numbers [17, 18]. The wind modeling technique (atmospheric boundary layer) in the model, is to model the wind using the wall of wind method with the Werner-Wengle wall model. This method proved more useful for representing a natural wind $[19,20]$.

Since the position of the smoke extraction opening is positioned at a height greater than $7 \mathrm{~m}$. In this case the effect of a high variation of the wind speed with respect to the height of the ground can be neglected. To meet engineering needs, Rehm et al. [21] have used the LES solver to estimate surface pressures on simple rectangular blocks under the effect of wind. In their study, they managed to show a good agreement and a positive performance (under normal operating conditions) between the simulation results and the experimental validation. Several other research studies have allowed experimental validation of the use of the FDS software in the case of the presence of wind pressure forces and for high firepower [22]. For the diagram in LES of the FDS software, it used a value of $\mathrm{y}^{+}=30$ so that the first cell that falls into the log layer is highly resolved [23].

\subsection{Convergence of Meshing}

The results obtained by the FDS numerical simulation software (version 6.5.3) remain poorly credible as long as the convergence of the mesh is not demonstrated. In this case, a manual convergence study was carried out in order to optimize the mesh [24]. This study consisted of creating a mesh using a reasonable number of elements, then to refine the mesh by a slight increase of its density, by recalculating it and comparing the results with the first calculation. The density of the mesh was continuously increased, and the results verified for satisfactory convergence. Figure 4 a shows a three-dimensional visualization of the mesh in the simulation domain. Figure $4 \mathrm{~b}$ shows the average values of the volume flow and the pressure exerted by the forces of wind pressure at the level of the smoke exhaust vent, for different mesh sizes. The mesh density retained is about 1.2 million elements.

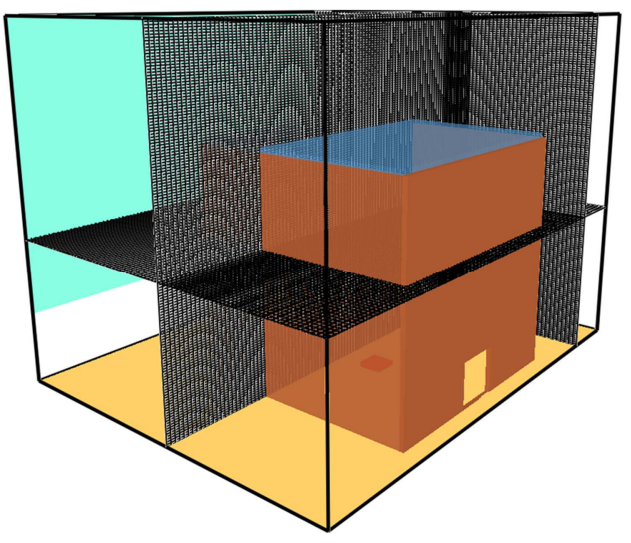

(a)

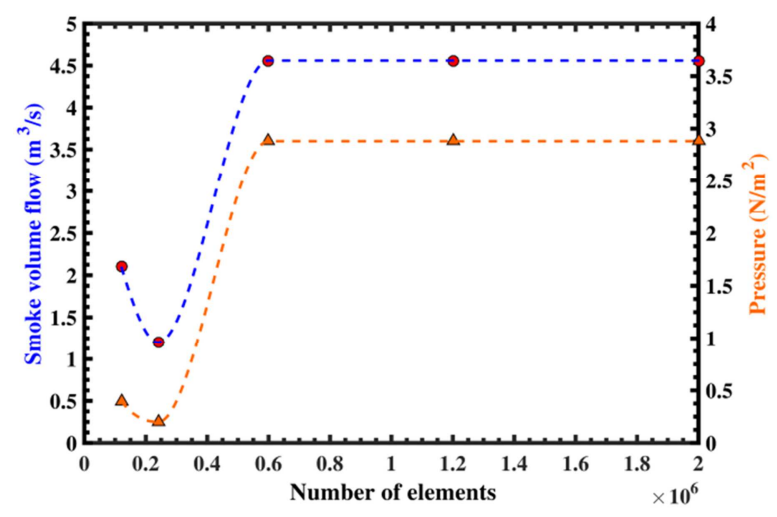

(b)

Figure 4. (a) Smokeview mesh visualization, (b) Smoke volume flow and pressure versus number of mesh elements for $V_{w}=2.0-m \cdot s^{-1}$ and $\psi_{t}=400-W$.

\subsection{Validation of the Model by FDS}

Figure 5 shows the values of the smoke extraction volume flow rate provided by the analytical model (steady state), as well as the values provided by the FDS software (variable regime) for two heat release rates $500-\mathrm{kW}$ and $1000-\mathrm{kW}$, and three wind speeds, $0.0-\mathrm{m} / \mathrm{s}, 2.0-\mathrm{m} / \mathrm{s}$ et $3.0-\mathrm{m} / \mathrm{s}$. It was observed that the values of the extraction volume flow rate predicted by the analytical model, aligned very well with the extraction volume flow values provided by the FDS digital simulation software. And that for coefficients of losses of charges $\mathrm{C}_{1}=3.5$ and $\mathrm{C}_{2}=$ 4.5 .

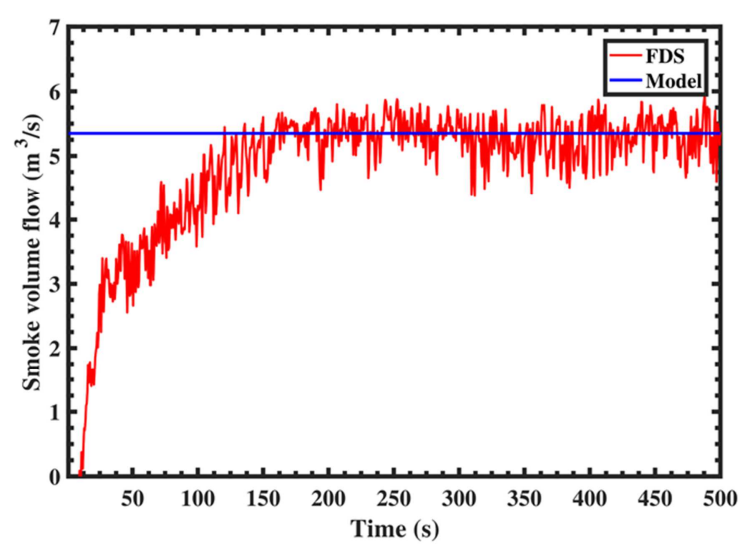

(a)



(b) 


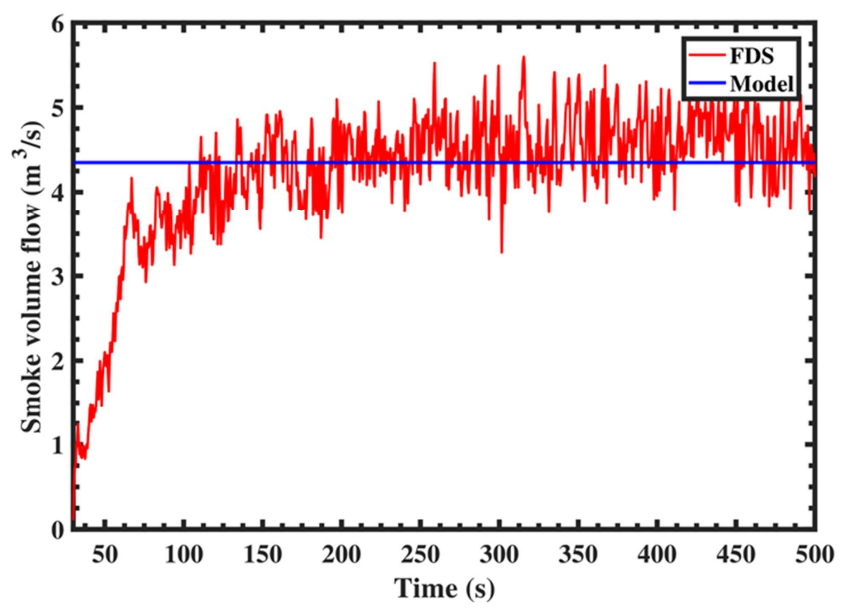

(c)



(d)



(e)

Figure 5. Model versus FDS: (a) $\psi_{t}=500-k W \& V_{w}=0-m \cdot s^{-1}$, (b) $\psi_{t}=1000$ $k W \& V_{w}=0-m \cdot s^{-1}$, (c) $\psi_{t}=500-k W \& V_{w}=-2 m \cdot s^{-1}$, (d) $\psi_{t}=1000-k W \& V_{w}=$ $2-m \cdot s^{-1}$, (e) $\psi_{t}=1000-k W \& V_{w}=3-m \cdot s^{-1}$.

It should be noted that the numerical values of $C_{1}$ and $C_{2}$ obtained may only be applicable to similar conditions in this study. It is suggested to use these constants with caution because of the limited data available in the literature [25]. We can therefore deduce that our analytical model, with a numerical resolution of equation 12 by the dichotomy method (Figure 3), and for moderate wind speeds, provides in steady state results to the results similar of CFD numerical simulation software.

\section{Analysis of Results and Discussion}

In cases of high wind speeds (i.e. when wind forces overcome the flotation forces of the smoke layer), it is interesting to compare the results provided by this analytical model and those obtained by the CFAST tool and the FDS software. That is, when the wind forces overcome the buoyancy forces of the smoke layer. This comparison makes it possible to understand the limits of the analytical model and the CFAST tool compared to FDS software in cases of the presence of the wind pressure forces. In this sense, wind speed and HRR are varied and the smoke volume flow is calculated using the three aforementioned approaches. Figures $6 \mathrm{a}$ and $6 \mathrm{~b}$ show the result of this comparison, for two different values of HRR and different wind speeds. It is observed that the values of the smoke volume flow provided by our model and by the CFAST code harmonize very well with the value provided by the FDS software for moderate wind speeds. As soon as the wind speed becomes, more than $3-\mathrm{m} / \mathrm{s}$ for HRR $500-\mathrm{kW}$ or 5 $\mathrm{m} / \mathrm{s}$ for HRR $1000-\mathrm{kW}$, the smoke extraction values provided by the developed model and the CFAST code differ from the values provided by the FDS software. This divergence is certainly due to the assumptions of calculations and approximations considered at the beginning of the model development. The start zone of the divergence of the results is illustrated in Figures 6a and $6 \mathrm{~b}$ by a circle. It can be observed that the analytical model developed, for moderate wind speeds, is closer to the results provided by the FDS software than to the results provided by the CFAST code. This approximation is close to the results provided by the FDS software, for low wind speed, is certainly related to the coefficients of pressure loss singular $C_{1}$ and $C_{2}$. Coefficients that have been adapted in the analytical model to the results provided by the FDS software. When the wind speed increases, we observe a flow of air entering by the exhaust vent, which explains the negative results for the smoke volume flow in the results of the FDS software.

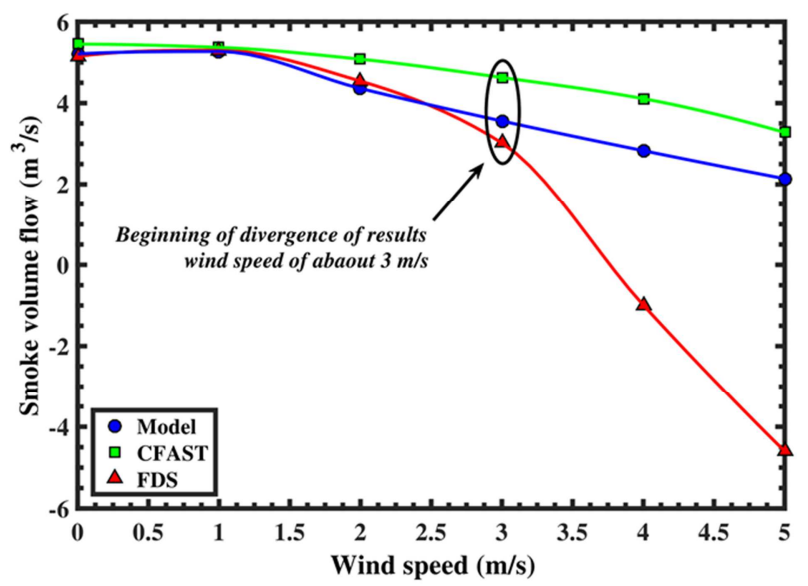

(a) 


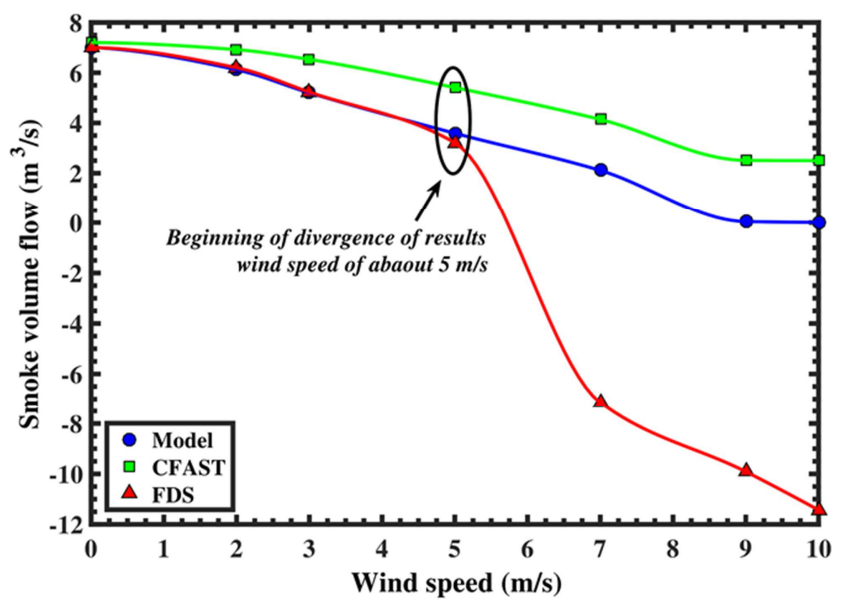

(b)

Figure 6. Model versus FDS \& CFAST: (a) Smoke volume flow versus $V_{w}$ for $\psi_{t}=500-k W$, (b) Smoke volume flow versus $V_{w}$ for $\psi_{t}=1000-k W$.

Figures $7 \mathrm{a}$ and $7 \mathrm{~b}$ show the values of the density isocontours obtained using the FDS software for a Heat release rate of $1000-\mathrm{kW}$ and two wind speeds of $5-\mathrm{m} / \mathrm{s}$ and $7-\mathrm{m} / \mathrm{s}$ respectively. The red zone represents the density of the air, which is $1.20-\mathrm{kg} / \mathrm{m}^{3}$. Any density below this value corresponds to the presence of hot smoke or flame.

We observe in Figure 7a (wind speed 5-m/s), bidirectional flow at the exhaust vent, and at the door of the room. This is because the buoyancy forces of the smoke layer begin to yield to the forces of wind pressure. In Figure $7 \mathrm{~b}$ which corresponds to a wind speed of $7-\mathrm{m} / \mathrm{s}$, an inverted unidirectional flow is observed at the exhaust vent and at the door of the room (air inlet opening). This inverted unidirectional flow is because the wind pressure forces have totally overcome the buoyancy forces of the smoke layer. This may explain the results of the negative flow shown in Figures $6 \mathrm{a}$ and $6 \mathrm{~b}$.



Figure 7. Isocontour density of the FDS software for 1000-kW and two wind speeds: (a). 5.0-, (b). 7.0-m.s.

\section{Approximation of the Optimal Section}

Current zone code limits include bidirectional or unidirectional (inverted) flow, and the inability to predict the smoke volume flow at high wind speeds [26]. Therefore, for high wind speeds, it is recommended to carry out a design study using the CFD software (type FDS). In all cases, the two scenarios in Figure 7 should be avoided for extracting smoke from the inside to the outside. Among the design solutions for this purpose we can mention the reduction of the size of the exhaust vent. Figures $8 \mathrm{a}$ and $8 \mathrm{~b}$ show the variation of the smoke volume flow as a function of the area of the exhaust vent, for two different HRR $(500-\mathrm{kW}$ and $1000-\mathrm{kW}$ ) and five wind speeds. The increase of the exhaust vent section allows a considerable extraction of smoke only when the wind speed is zero. In the case of a non-zero wind speed (wind resistance is present), it is observed that the variation of the exhaust vent section will provide a maximum extraction of the smoke for an optimal section of sizing.

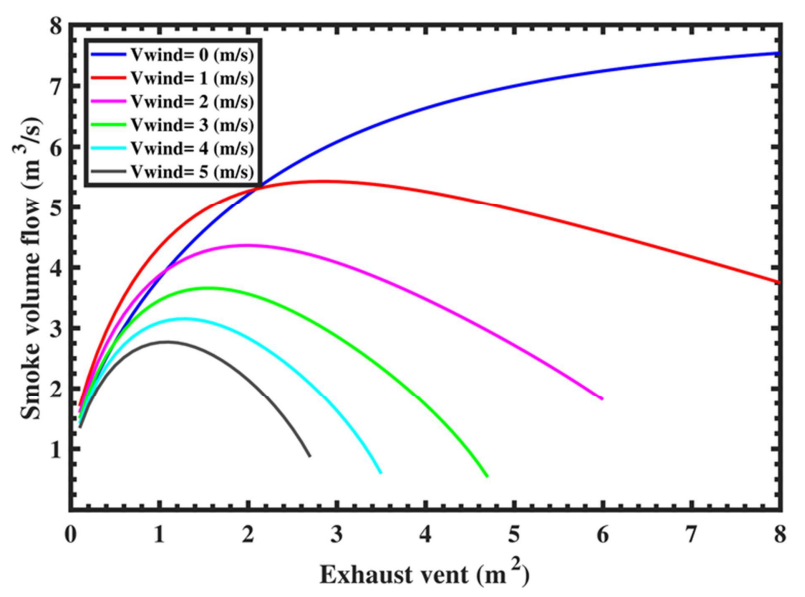

(a)



(b)

Figure 8. Exhaust vent versus Smoke volume flow: (a) $H R R=500-\mathrm{kW}$, (b) $H R R=1000-k W$.

To produce contour lines with response intervals that represent, optimal section and maximum flow according to the input parameters of the model $\left(\psi_{\mathrm{t}}, \mathrm{H}, \mathrm{S}_{1}\right.$ et $\left.\mathrm{V}_{\mathrm{w}}\right)$ the RSM experimental analysis was used [27], which is a technique of statistical analysis and, which has the advantage of being easy to apply for the prediction of output responses. Table 2 shows the factors and levels used in the planning of 
numerical simulations. As a result, 4 factors with 4 levels are considered.

Table 2. Factors and levels of the numerical design.

\begin{tabular}{ll}
\hline Factors & Levels \\
\hline $\mathrm{HRR}(\mathrm{kW})$ & $400,500,700$ and 1000 \\
$\mathrm{H}(\mathrm{m})$ & $6,7,9$, and 10 \\
$\mathrm{~S}_{1}\left(\mathrm{~m}^{2}\right)$ & $2,2.5,4$ and 4.5 \\
$\mathrm{~V}_{\mathrm{w}}\left(\mathrm{m} \cdot \mathrm{s}^{-1}\right)$ & $1,2,4$ and 5 \\
\hline
\end{tabular}

Table 3 presents the 4 -factors $\mathrm{L}_{8}$ matrix, with the results of measurements of the optimal section $\hat{\mathrm{S}}_{2}$ of the exhaust vent which will produce a maximum volume flow of smoke
Qmax.

Figures $9 \mathrm{a}$ and $9 \mathrm{~b}$ show the estimated response surfaces with the Thin-plate-spline interpolation method [28] for the variation of the value of the optimal section and the maximum flow as a function of the wind speed, heat release rate and the height between the two openings. These contour lines correspond to the intervals of the parameters in Table 2. This representation of contour lines can be used for the prediction of the optimal sizing section, and the maximum smoke volume flow, because it has the advantage of being easy to use in practice by users of the model.

Table 3. $L_{8}$ matrix and results of numerical simulations.

\begin{tabular}{|c|c|c|c|c|c|c|}
\hline \multirow{2}{*}{ Tests } & \multicolumn{4}{|l|}{ Factors } & \multicolumn{2}{|c|}{ Responses } \\
\hline & $\psi_{\mathrm{t}}(\mathrm{kW})$ & H (m) & $S_{1}\left(m^{2}\right)$ & $V_{w}\left(m \cdot s^{-1}\right)$ & $\hat{\mathrm{S}}_{2}\left(\mathrm{~m}^{2}\right)$ & $Q_{\max }\left(m^{3} \cdot s^{-1}\right)$ \\
\hline 1 & 400 & 6 & 2.0 & 1.0 & 1.5 & 3.13 \\
\hline 2 & 500 & 7 & 2.5 & 2.0 & 1.4 & 3.35 \\
\hline 3 & 700 & 9 & 4.0 & 4.0 & 1.4 & 3.98 \\
\hline 4 & 1000 & 10 & 4.5 & 5.0 & 1.5 & 4.80 \\
\hline 5 & 400 & 10 & 2.5 & 4.0 & 1.2 & 2.96 \\
\hline 6 & 500 & 9 & 2.0 & 5.0 & 0.9 & 2.59 \\
\hline 7 & 700 & 7 & 4.5 & 1.0 & 2.7 & 5.62 \\
\hline 8 & 1000 & 6 & 4.0 & 2.0 & 1.5 & 4.63 \\
\hline
\end{tabular}

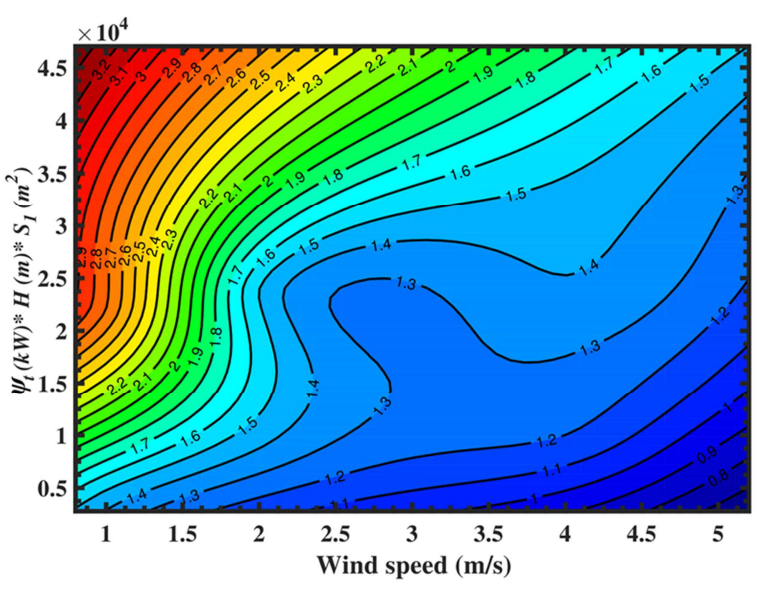

(a)

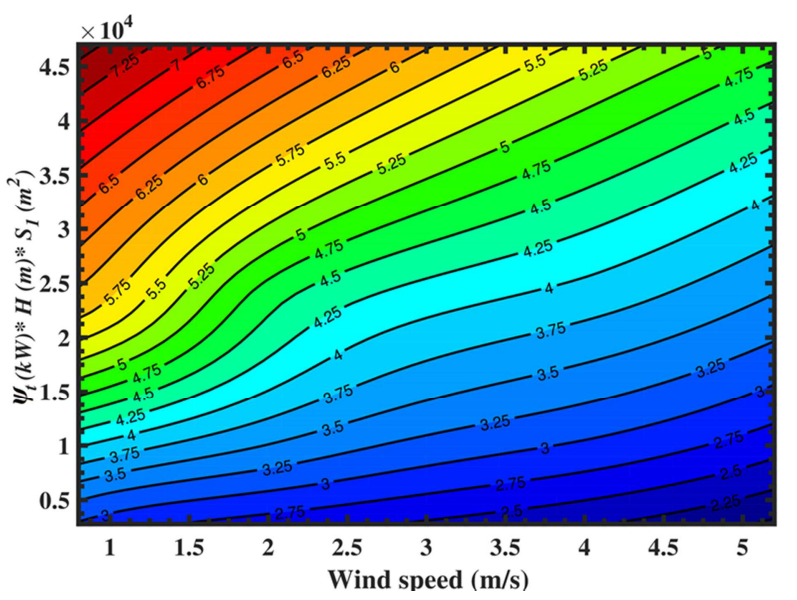

(b)

Figure 9. Contour plot: (a) Optimal section of the exhaust vent ( $\left.\mathrm{m}^{2}\right)$, (b) Maximum smoke volume flow $\left(\mathrm{m}^{3} \cdot \mathrm{s}^{-1}\right)$.

\section{Conclusions}

In this study, the natural evacuation of fire smoke through an exhaust vent subjected to wind pressures was evaluated by an analytical model and validated by CFD numerical simulation software. The major findings are summarized below:

(1) The analytical model developed for a simple geometry, in steady state, using the simplifying assumptions of Archimedes at equilibrium, Bernoulli for pressure, and correlations of Heskestad for the characteristics of the plume from a heptane pool fire, allowed to formulate a general equation of the flow rate balance including the wind speed.

(2) The resolution of the flow balance equation, by the numerical method of dichotomy, has given the numerical value of the smoke layer level positioning. Which is an indispensable piece of information for Heskestad correlations to express the value of the volume flow of smoke extraction.

(3) The numerical validation of the analytical model by the FDS software (version 6.5.3) confirmed the accuracy of the model under permanent regime, for moderate wind speeds, and also to show the validation limits of the simplifying assumptions adopted for high wind speeds.

(4) For high wind speeds, it has been shown that reducing the size of the smoke exhaust vent can be a possible solution to allow the buoyancy forces of the smoke layer to prevail against the forces of wind pressure. The representation of contour lines using the response surfaces has provided easy to interpret control charts for predicting the optimal section of 
the smoke exhaust vent.

It would be interesting to consider completing this study by: an analysis of variance to see the exact influence of each parameter on the final output response of the model, by including different geometric shape of the smoke exhaust vent; an integration of a significant temperature difference between the inside and the outside (as it is in Canada during the winter season), and thus to understand the influence of the temperature of the walls on the thermal draft of the smoke. We believe that this type of approach proposed in this study is the most appropriate way to develop control models for concrete case studies, such as the positive pressure ventilation (PPV) of the Cottages of North America.

\section{Nomenclature}

\begin{tabular}{|c|c|}
\hline $\mathrm{g}$ & Gravity acceleration, $\mathrm{m} \cdot \mathrm{s}^{-2}$ \\
\hline $\mathrm{C}_{1}$ & Load loss coefficient of the door, \\
\hline $\mathrm{C}_{2}$ & Load loss coefficient of the smoke vent, \\
\hline $\mathrm{Q}_{\mathrm{w}}$ & Air flow rate, $\mathrm{m}^{3} \cdot \mathrm{s}^{-1}$ \\
\hline $\mathrm{Q}_{2}$ & Smoke flow rate, $\mathrm{m}^{3} \cdot \mathrm{s}^{-1}$ \\
\hline $\mathrm{Q}_{\mathrm{ext}}$ & Volume flow at smoke vent, $\mathrm{m}^{3} \cdot \mathrm{s}^{-1}$ \\
\hline $\mathrm{Q}_{\max }$ & Maximum volume flow at smoke vent, $\mathrm{m}^{3} \cdot \mathrm{s}^{-1}$ \\
\hline$Q_{v}$ & $\begin{array}{l}\text { Smoke volume rate entering in the layer of smoke, } \\
\mathrm{kg} \cdot \mathrm{m}^{-3}\end{array}$ \\
\hline$\rho^{*}(\mathrm{z})$ & Density of the smoke layer at a height $\mathrm{z}, \mathrm{kg} \cdot \mathrm{m}^{-3}$ \\
\hline$d(z)$ & Diameter of the plume disc at a height $\mathrm{z}, \mathrm{m}$ \\
\hline$\rho$ & Density of air, kg.m $\mathrm{m}^{-3}$ \\
\hline $\mathrm{D}$ & Diameter of heptane container, $\mathrm{m}$ \\
\hline h & $\begin{array}{l}\text { Distance between the lower part of the smoke layer } \\
\text { and the center of the opening } \mathrm{S}_{2}, \mathrm{~m}\end{array}$ \\
\hline $\mathrm{H}$ & $\begin{array}{l}\text { Distance between the centers of the two openings, } \\
\mathrm{m}\end{array}$ \\
\hline $\mathrm{L}$ & Height of the door of the room, $\mathrm{m}$ \\
\hline $\mathrm{V}_{\mathrm{w}}$ & Wind speed, $\mathrm{m} . \mathrm{s}^{-1}$ \\
\hline $\mathrm{S}_{1}$ & Section of the door, $\mathrm{m}^{2}$ \\
\hline $\mathrm{S}_{2}$ & Section of the smoke vent, $\mathrm{m}^{2}$ \\
\hline$\hat{\mathrm{S}}_{2}$ & Optimal section of the smoke vent, $\mathrm{m}^{2}$ \\
\hline$\psi_{\mathrm{t}}$ & Heat release rate (HRR), MW \\
\hline $\mathrm{P}_{0}$ & Fluid pressure at point $0, \mathrm{~Pa}$ \\
\hline $\mathrm{P}_{1}$ & Fluid pressure at point $1, \mathrm{~Pa}$ \\
\hline $\mathrm{P}_{2}$ & Fluid pressure at point $2, \mathrm{~Pa}$ \\
\hline $\mathrm{P}_{3}$ & Fluid pressure at point $3, \mathrm{~Pa}$ \\
\hline $\mathrm{S}$ & Local floor area, $\mathrm{m}^{2}$ \\
\hline $\mathrm{u}(\mathrm{z})$ & $\begin{array}{l}\text { Mass transfer speed between the plume and the } \\
\text { smoke layer at a height } \mathrm{z}, \mathrm{m}_{\mathrm{s}}^{-1}\end{array}$ \\
\hline
\end{tabular}

\section{Conflict of Interest}

On behalf of all authors, the corresponding author states that there is no conflict of interest.

\section{References}

[1] Purkiss, John A. and LI, Long-Yuan. Fire safety engineering design of structures. CRC Press, 2013.
[2] Rasbash, D. J. Fire safety objectives for buildings. Fire technology, 1996, vol. 32, no 4, p. 348- 350.

[3] Anderson, John D. (1995). Computational Fluid Dynamics: The Basics With Applications. McGraw-Hill Science.

[4] Patankar, Suhas. Numerical heat transfer and fluid flow. CRC press, 1980.

[5] Babrauskas, Vytenis. Heat release rates. In : SFPE handbook of fire protection engineering. Springer New York, 2016. p. 799-904.

[6] Wojciech, Węgrzyński and Grzegorz, Krajewski. Combined Wind Engineering, Smoke Flow and Evacuation Analysis for a Design of a Natural Smoke and Heat Ventilation System. Procedia Engineering, 2017, vol. 172, p. 1243-1251.

[7] Gupta, R. (1997). Air-handling design: A balancing act. Consulting - Specifying Engineer, 22(4), 74-76.

[8] Dalgliesh, William Alan and Boyd, Donald W. Le vent sur les bâtiments. 1964.

[9] P. F. Linden, The Fluid Mechanics of Natural Ventilation, Annu. Rev. Fluid Mech. 1999. 31:201-38.

[10] Shames, Irving Herman and Shames, Irving H. Mechanics of fluids. New York: McGraw-Hill, 1982.

[11] Welty, James R., Wicks, Charles E., Rorrer, Gregory, Fundamentals of momentum, heat, and mass transfer. John Wiley \& Sons, 2009.

[12] Hunt, G. R. and Linden, P. P. The fluid mechanics of natural ventilation-displacement ventilation by buoyancy-driven flows assisted by wind. Building and Environment, 1999, vol. 34, no 6, p. 707-720. MLA.

[13] Heskestad, Gunnar. Engineering relations for fire plumes. Fire Safety Journal, 1984, vol. 7, no 1, p. 25-32.

[14] T. Dekker, "Finding a zero by successive linear interpolation" B. Dejon (ed.) P. Henrici (ed.), Constructive aspects of the fundamental theorem of algebra, Wiley (1969) pp. 37-48.

[15] Minoux, M. (1986). Mathematical programming: theory and algorithms. John Wiley \& Sons.

[16] Kevin McGrattan, Simo Hostikka, Randall McDermott, Jason Floyd, Craig Weinschenk, Kristopher Overholt, Fire Dynamics Simulator User's Guide, NIST Special Publication 1019, Sixth Edition, 2017, FDS Version 6.5.3.

[17] Deardorff, James W. A numerical study of three-dimensional turbulent channel flow at large Reynolds numbers. Journal of Fluid Mechanics, 1970, vol. 41, no 2, p. 453-480.

[18] Massey, Bernard Stanford and Ward-Smith, John. Mechanics of fluids. CRC Press, 1998.

[19] Kalnay, Eugenia. Atmospheric modeling, data assimilation and predictability. Cambridge university press, 2003.

[20] Stephen B. Pope. Turbulent Flows. Cambridge University Press, 2000.

[21] R. Rehm, K. McGrattan, H. Baum, and E. Simiu. An Efficient Large Eddy Simulation Algorithm for Computational Wind Engineering: Application to Surface Pressure Computations on a Single Building. NISTIR 6371, National Institute of Standards and Technology, August 1999. 
[22] Kevin McGrattan, Simo Hostikka, Randall McDermott, Jason Floyd, Craig Weinschenk, Kristopher Overholt, Fire Dynamics Simulator Technical Reference Guide Volume 3: Validation, NIST Special Publication 1018-3 Sixth Edition, January 18, 2017 FDS Version 6.5.3.

[23] H. Werner and H. Wengle. Large-eddy simulation of turbulent flow over and around a cube in a plate channel. In 8th Symposium on Turbulent Shear Flows, pages 155-168, Munich, Germany, 1991. Technische University Munich.

[24] Leveque, Randall J. Numerical methods for conservation laws. Springer Science \& Business Media, 1992.

[25] Dahai Qi, Liangzhu Wang, and Radu Zmeureanu, The Effects of Non-uniform Temperature Distribution on Neutral Plane Level in Non-adiabatic High-Rise Shafts During Fires, Fire Technology, 2017, vol. 53, no 1, p. 153-172.

[26] Richard D. Peacock, Paul A. Reneke, Glenn P. Forney, CFAST - Consolidated Model of Fire Growth and Smoke Transport (Version 7) Volume 2: User's Guide, NIST Technical Note 1889v2, 2017 CFAST Version 7.2.2.

[27] R. H. Myers, Response Surface Methodology, Allyn and Bacon, Boston, USA, 1971.

[28] Harder, Robert L., and Robert N. Desmarais. "Interpolation using surface splines.", Nasa Langley Research Center, Journal of aircraft 9.2 (1972): 189-191. 